\title{
A 5'-terminal stem-loop structure can stabilize mRNA in Escherichia coli
}

\author{
Sheri A. Emory, ${ }^{1}$ Philippe Bouvet, ${ }^{1,2}$ and Joel G. Belasco ${ }^{1,3}$ \\ ${ }^{1}$ Department of Microbiology and Molecular Genetics, Harvard Medical School, Boston, Massachusetts 02115 USA; \\ ${ }^{2}$ Laboratoire de Biologie et Genetique du Developpement, Universite de Rennes I, 35042 Rennes Cedex, France
}

The $5^{\prime}$-untranslated region of the long-lived Escherichia coli ompA transcript functions as an mRNA stabilizer capable of prolonging the lifetime in $E$. coli of a number of heterologous messages to which it is fused. To elucidate the structural basis of differential mRNA stability in bacteria, the domains of the ompA $5^{\prime}$-untranslated region that allow it to protect mRNA from degradation have been identified by mutational analysis. The presence of a stem-loop no more than 2-4 nucleotides from the extreme ${ }^{5}$ terminus of this RNA segment is crucial to its stabilizing influence, whereas the sequence of the stem-loop is relatively unimportant. The potential to form a hairpin very close to the $5^{\prime}$ end is a feature common to a number of stable prokaryotic messages. Moreover, the lifetime of a normally labile message (bla mRNA) can be prolonged in $E$. coli by adding a simple hairpin structure at its $5^{\prime}$ terminus. Accelerated degradation of ompA mRNA in the absence of a $5^{\prime}$-terminal stem-loop appears to start downstream of the $5^{\prime}$ end. We propose that $E$. coli messages beginning with a single-stranded RNA segment of significant length are preferentially targeted by a degradative ribonuclease that interacts with the mRNA $5^{\prime}$ terminus before cleaving internally at one or more distal sites.

[Key Words: mRNA stability; 5'-untranslated region; Escherichia coli; gene regulation; ompA; RNA structure]

Received October 18,1991; revised version accepted November 27, 1991.

Degradation of mRNA is a cellular process that is highly important for controlling gene expression. The capacity to degrade mRNA is essential to the ability of cells to alter their patterns of protein synthesis rapidly in response to their changing needs. In addition, the steadystate cellular concentration of a continuously synthesized message is directly proportional to its half-life. The lifetimes of individual messages can vary widely within a single cell. For instance, mRNA half-lives in Escherichia coli range from seconds to nearly an hour, with an average lifetime of 2-4 min (Pedersen et al. 1978; Nilsson et al. 1984; Donovan and Kushner 1986; Emory and Belasco 1990). Despite the importance of mRNA instability to gene regulation, the mechanisms and structural determinants of prokaryotic mRNA decay are not well understood (Kennell 1986; Belasco and Higgins 1988).

Elements at the $5^{\prime}$ and $3^{\prime}$ ends of bacterial and phage messages have been implicated in mRNA stabilization. Most prokaryotic mRNAs end in a $3^{\prime}$-terminal stemloop structure, which serves as a protective barrier against degradation by $3^{\prime}$ exoribonucleases (Belasco et al. 1985; Mott et al. 1985; Newbury et al. 1987; Chen et al. 1988). However, for bacterial mRNAs that end with a $3^{\prime}$ hairpin, there is hardly any evidence to indicate that stability differences in vivo result from differential rates of exonucleolytic penetration of these 3 ' stem-loop struc-

${ }^{3}$ Corresponding author. tures (Belasco et al. 1986; Chen et al. 1988; Chen and Belasco 1990). Instead, it appears that the disparate lifetimes of most prokaryotic mRNAs are controlled by decay determinants located upstream of the $3^{\prime}$ end. Especially noteworthy are a small number of 5 '-terminal mRNA segments that have been shown to stabilize heterologous messages to which they are fused. These $5^{\prime}$ mRNA stabilizers comprise the $5^{\prime}$-untranslated region (UTR) of certain stable bacterial and phage messages, such as the ompA transcript of E. coli, the ermC and ermA transcripts of Bacillus subtilis and Staphylococcus aureus, and the gene 32 message of phage $\mathrm{T} 4$, as well as a 5' segment of the phage $\lambda p_{\mathrm{L}}$ transcript (Yamamoto and Imamoto 1975; Gorski et al. 1985; Belasco et al. 1986; Bechhofer and Dubnau 1987; Sandler and Weisblum 1988). Apparently, these 5 ' elements are able to protect mRNA from attack by an important cellular ribonuclease that initiates mRNA degradation in vivo; the identity of this key degradative enzyme remains uncertain. Most of the known $5^{\prime}$ mRNA stabilizers function only under special conditions. For example, the gene 32 $5^{\prime}$ UTR can increase message lifetimes only in T4-infected cells (Gorski et al. 1985), and stabilization of mRNA by the erm $C$ and ermA 5' UTRs requires ribosome stalling induced by an antibiotic that inhibits translation (Bechhofer and Dubnau 1987; Sandler and Weisblum 1988). Similarly, message stabilization by the $5^{\prime}$ portion of the $\lambda p_{\mathrm{L}}$ transcript is most pronounced only 
after prolonged $\lambda$ infection (Yamamoto and Imamoto 1975).

In contrast, the ompA $5^{\prime}$ UTR can stabilize mRNA in $E$. coli under normal conditions of rapid cell growth (Belasco et al. 1986; Emory and Belasco 1990). This RNA segment is derived from the ompA gene transcript, which encodes a major $E$. coli outer membrane protein (OmpA). In cells growing rapidly at $30^{\circ} \mathrm{C}$, the omp $A$ message decays with a half-life of $\sim 17 \mathrm{~min}$, making it one of the most stable mRNAs in E. coli (von Gabain et al. 1983). The lifetime of $o m p A$ mRNA is growth rate regulated and falls by as much as a factor of 4 in slowly growing cells (Nilsson et al. 1984). Growth rate regulation of ompA mRNA stability, like the longevity of the ompA transcript under conditions of rapid growth, is determined by the 133-nucleotide ompA 5' UTR, which can confer both of these properties onto other messages to which it is joined (Emory and Belasco 1990).

As the lifetimes of a variety of labile messages can be prolonged by fusion to the ompA 5' UTR (Belasco et al. 1986; M. Hansen and J. Belasco, unpubl.), it appears that many E. coli mRNAs are degraded via a common pathway against which this 5' RNA segment provides protection. Message stabilization by the ompA 5' UTR is not an indirect consequence of close ribosome spacing, which theoretically might sterically hinder ribonuclease attack (Lundberg et al. 1988; Emory and Belasco 1990; M. Hansen and J. Belasco, unpubl.). Instead, this RNA segment seems to act directly to protect mRNA from degradation by a ribonuclease that responds to one or more elements near the mRNA $5^{\prime}$ end. Both the secondary structure of the ompA 5' UTR and its ability to function as a growth-rate-regulated mRNA stabilizer are highly conserved among enteric bacteria (Chen et al. 1991). However, the identity of the specific ompA 5' UTR structural features that are important for mRNA stabilization has not been explored previously.

To elucidate the mechanism of mRNA stabilization by the E. coli ompA 5' UTR, we have dissected this RNA segment to identify the structural components that can protect mRNA from degradation in E. coli. Our studies reveal that the presence of a stem-loop at or very near the extreme $5^{\prime}$ terminus of the ompA $5^{\prime}$ UTR is essential for its function as a potent mRNA stabilizer. Furthermore, the half-life of a normally labile $E$. coli message can be prolonged by adding a simple stem-loop at its $5^{\prime}$ end. The $5^{\prime}$ stem-loop protects ompA mRNA from degradation that appears to begin downstream of the 5 ' end. By defining important aspects of the substrate specificity of the $E$. coli mRNA degradation machinery, these findings provide key insights into both the structural basis of differential message stability in bacteria and the mechanism of mRNA decay.

\section{Results}

Two domains of the ompA 5' UTR are important for mRNA stabilization

We have shown previously that the $E$. coli omp $A 5^{\prime}$ UTR comprises two imperfect stem-loop structures (hpl and hp2) and two single-stranded RNA segments (ss1 and ss2) (Fig. 1; Chen et al. 1991). The ompA 5' UTR was dissected to identify the structural domains responsible for its activity as an mRNA stabilizer in rapidly growing E. coli cells. Various 5' UTR segments were deleted from a plasmid-borne copy of a pseudo-wild-type ompA gene (omp $A+4)$ that encodes a transcript virtually identical in sequence and stability to the wild-type ompA message (Emory and Belasco 1990). These deleted segments corresponded to one or more RNA structural domains of the ompA $5^{\prime}$ UTR upstream of the ribosome-binding site (Fig. 1). Plasmids encoding the resulting mutant ompA messages were introduced into $E$. coli strain C600S, and total cellular RNA was isolated from rapidly growing cultures at time intervals after transcription inhibition with rifampicin. Degradation of each mutant message and of the endogenous wild-type $E$. coli ompA message was monitored simultaneously by $S 1$ analysis of these RNA samples (Table 1). The parallel analysis of the decay of wild-type ompA mRNA provided an internal standard that facilitated interpretation of stability differences among the various mutant transcripts.

Two distinct structural domains appear to contribute to mRNA stabilization by the ompA 5' UTR. One is the 5 '-terminal stem-loop structure (hpl; Fig. 1), whose precise deletion reduces the half-life of $\operatorname{omp} A$ mRNA by a factor of 3 to just $5.7 \pm 0.4 \min$ (ompA $\Delta 64$; Fig. 2, left).

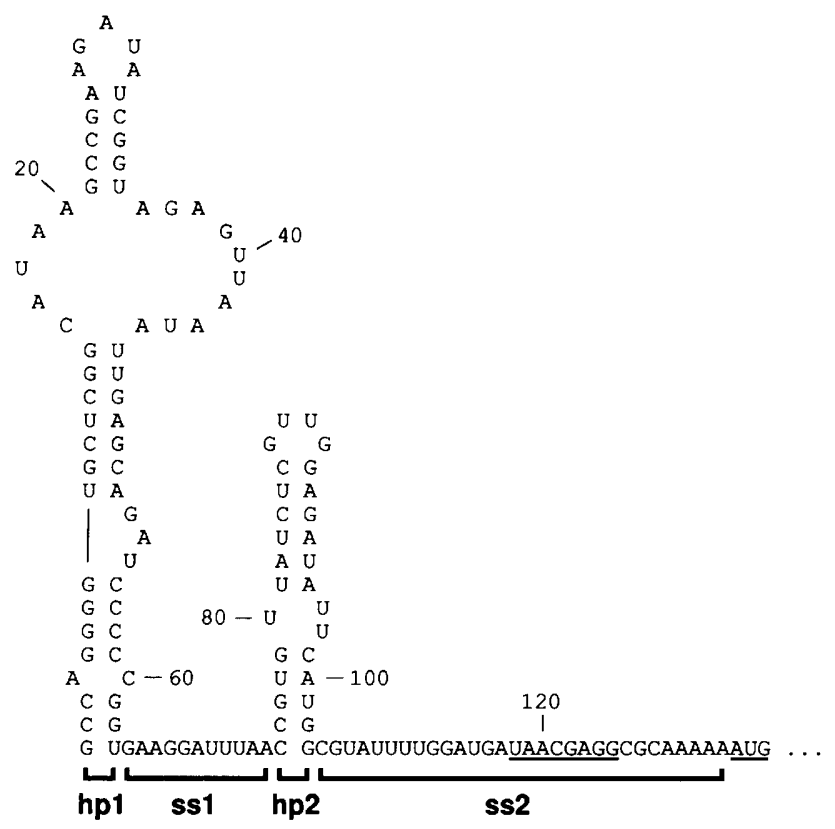

Figure 1. Secondary structure of the ompA 5' UTR. Brackets delineate the boundaries of the four secondary-structure domains within this RNA segment (Chen et al. 1991): hp1 (nucleotides 1-63), ss1 (64-74), hp2 (75-103), and ss2 (104-133). The Shine-Dalgarno element and translation initiation codon are underlined. Precise 5 '-end mapping by primer extension shows that roughly equal numbers of $E$. coli ompA transcripts begin with the indicated $5^{\prime}$-terminal nucleotide or with a cytosine residue 1 nucleotide upstream (data not shown). 
The other is a single-stranded RNA segment (ss2; Fig. 1), the $3^{\prime}$ portion of which contains the ribosome-binding site. The stability of $o m p A$ mRNA is halved by deleting from ss2 an 11-nucleotide RNA segment (5'-ss2) located a few nucleotides upstream of the $\operatorname{omp} A$ Shine-Dalgarno sequence (ompAD104-114; Fig. 2, middle). Larger deletions that remove either of these two elements (hp1 or $5^{\prime}$-ss2) also destabilize the ompA message (ompAD104, ompA $\Delta 115$; Table 1). In contrast, deletion of the internal hairpin (hp2) within the $5^{\prime}$ UTR and of the singlestranded segment (ssl) between hpl and hp2 (ompA $\Delta 65$ 104 , ompA $\Delta 74-103$ ) has little or no effect on the degradation rate of the ompA transcript (Fig. 2, middle; Table 1). All of these deletions leave the ompA ribosome-binding site intact, and none impair translation of ompA mRNA (Emory and Belasco 1990; Emory 1991).

\section{Stabilization by the 5'-terminal stem-loop is independent of its sequence}

The 5' UTRs of ompA mRNA from Serratia marcescens and Enterobacter aerogenes function as effective mRNA stabilizers in $E$. coli despite extensive sequence differences in both hp1 and hp2 (Chen et al. 1991). To assess the importance of the sequence of hpl to ompA mRNA stability, the degradation of variant $E$. coli ompA messages with altered $5^{\prime}$-terminal hairpins was examined (Fig. 3; Table 2). Truncation of hpl by deleting 44 nucleotides from its top reduces the h-lf-life of the ompA message by $<28 \%$ (ompA $\Delta$ 9-52). Moreover, replacement of hpl with an entirely different and perfectly paired stemloop structure (hp*: GAUCGCCCACCGGCAGCUGCCGGUGGGCGAUC) also has little effect on the stability of the ompA transcript (ompAD64*). Perhaps surprisingly, deletion of the leading strand of hpl does not accelerate degradation of the message (ompA 429 ). However, the longevity of this mutant $\operatorname{omp} A$ transcript can be explained by its ability to fold so as to create an alternative stem-loop within 2 nucleotides of the mRNA $5^{\prime}$ end. Formation of this alternative hairpin structure is supported by the results of RNA methylation analysis in vivo with dimethylsulfate (DMS) (Fig. 3), a membranepermeating reagent that methylates most unpaired adenosine and cytosine residues, as well as some unpaired uridine nucleotides (methylation of guanosine residues by DMS is not sensitive to base-pairing) (Mayford and Weisblum 1989|. The stability of three distinct ompA messages with $5^{\prime}$-terminal stem-loop structures strikingly different from that of the wild-type transcript shows that the presence of this terminal stem-loop is more important than its sequence to the activity of the ompA mRNA stabilizer.

The location of the 5' stem-loop is crucial to message stability

To determine whether it is the simple presence of hpl or its proximity to the $5^{\prime}$ end of the $\operatorname{omp} A$ transcript that is important for its contribution to mRNA stability, the effect of adding nucleotides upstream of this hairpin was examined. With the aid of a computer program for predicting RNA secondary structure (Jaeger et al. 1989), the sequences of the $5^{\prime}$ extensions were chosen to minimize the possibility that they would participate in base-pairing. Plasmids encoding mutant ompA transcripts with three different $5^{\prime}$ extensions $(o m p A+12 a$ : AGACUUUACAUC . . ; ompA + 16a: GAUCAGACUUUACAUC ...; or ompA+16b: GAUCUAUACUAUAACC...) were constructed (Table 3). These 12- to 16-nucleotide extensions were expected to add 10-15 unpaired nucleotides to the ompA 5' end and to augment ompA hpl by 1-2 bp at its base, owing to pairing of the last 1-2 nucleotides of each extension ( $\mathrm{C}$ or $\mathrm{UC}$ ) with the first 1-2 nucleotides of segment ss1 (G or GA). [Base-pairing of these two ss1 nucleotides has no effect on ompA mRNA stability (Emory and Belasco 1990).] The half-lives of omp $A+12 a$, $o m p A+16 a$, and ompA+16b mRNA were then measured in strain C600S (Fig. 4). In every case, the addition of 12-16 nucleotides to the $5^{\prime}$ end was found to reduce the ompA mRNA half-life to just 3-6 min. This acceleration of decay is similar to that resulting from deletion of the 5 '-terminal hairpin.

Because ompA mRNA is destabilized by three different 5' extensions, two of which (omp $A+12 a$ and $o m p A+16 b)$ have entirely distinct sequences, the destabilizing influence of these $5^{\prime}$ extensions is likely to be the result of internalization of what is normally a $5^{\prime}$ terminal hairpin and not to possible disruption of the secondary structure of the ompA 5' UTR by the basepairing potential of the added nucleotides. This conclusion is supported by the finding that nearly full longevity is restored to these mutant messages by adding a new $5^{\prime}$-terminal hairpin $\left(\mathrm{hp}^{\star}\right)$ upstream of the $5^{\prime}$ extensions $\left(o m p A+12 a^{*}\right.$ and $o m p A+16 b^{*}$; Table 3; Fig. 4), as this stabilizing modification should not interfere with the base-pairing potential of the original 12- to 16-nucleotide $5^{\prime}$ extensions. Therefore, it is the $5^{\prime}$-terminal location of the single-stranded extensions, rather than their mere presence, that accelerates degradation of ompA mRNA. Further confirmation that these extensions do not alter the structure of the ompA 5' UTR was obtained by chemically probing the secondary structure of $o m p A+12 a, o m p A+16 a$, and omp $A+16 b$ mRNA. This was accomplished in vivo by using dimethylsulfate (DMS). Also tested was the susceptibility of these messages to alkylation in vitro by DMS and by 1-cyclohexyl3-(2-morpholinoethyl)carbodiimide metho- $p$-toluenesulfonate (CMCT), which alkylates unpaired uridine residues and, to a lesser extent, unpaired guanosine residues (Moazed et al. 1986). When the DMS and CMCT alkylation sites within these 5' UTRs were mapped by primer extension (Fig. 5) and compared with data from a similar analysis of wild-type ompA mRNA (Chen et al. 1991), it was evident that the ompA+12a, ompA+16a, and omp $A+16 b$ extensions do not perturb the overall secondary structure of the rest of the $5^{\prime}$ UTR and that, as expected, the first 14-15 nucleotides of these $5^{\prime}$ extensions apparently are single stranded. 


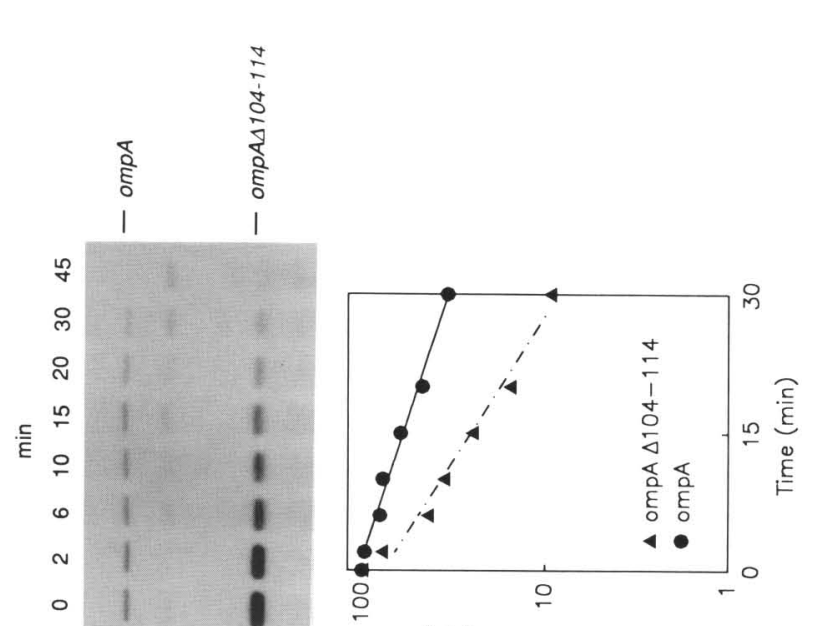

(\%) Guluipuray Nym

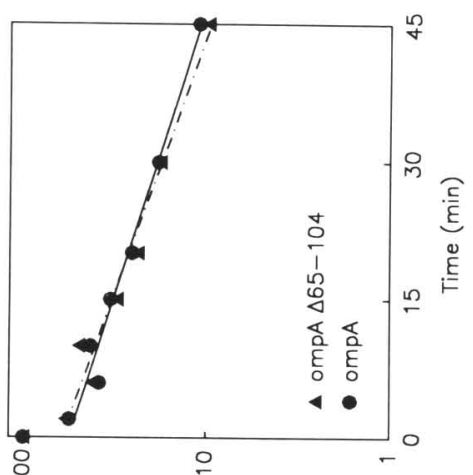

(\%) Gu!u!oury $\forall$ Nym


(\%) Бu!u!omay $\forall$ Nym

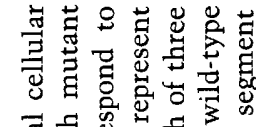

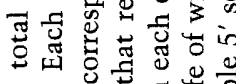

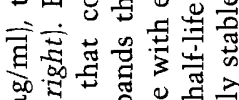

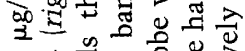

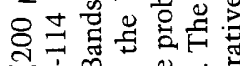

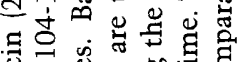

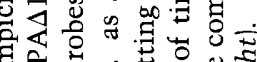

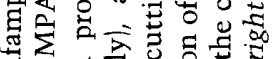

可造总总出

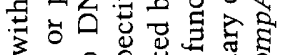

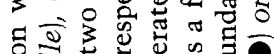

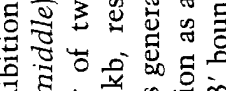

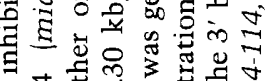



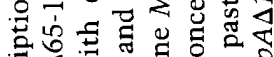

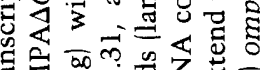

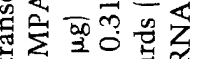
으 0 몀

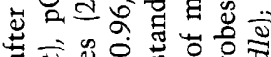
कैषे

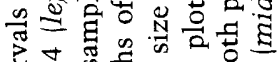

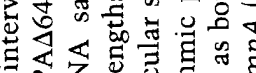

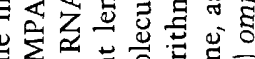

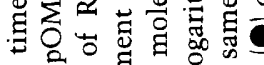

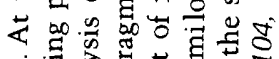

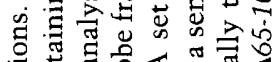

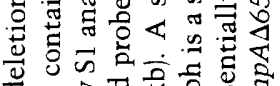

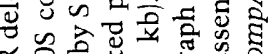

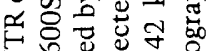

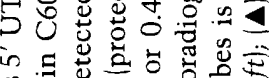

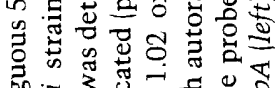

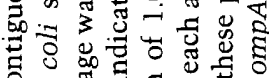

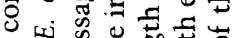


苟声芯芯的志 चु उ

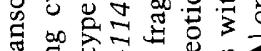

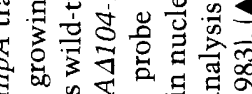
द्व

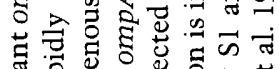

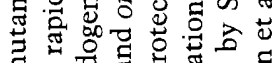

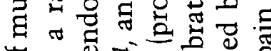

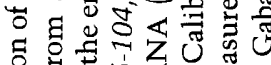

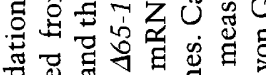

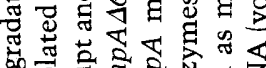

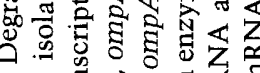



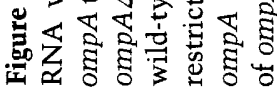


Table 1. Half-lives of mutant ompA transcripts lacking 5' UTR segments

\begin{tabular}{|c|c|c|c|}
\hline$o m p A$ allele & $\begin{array}{l}5^{\prime} \text { UTR } \\
\text { structure }^{a}\end{array}$ & $\begin{array}{l}\text { Mutant } \\
\text { half-life } \\
\text { (min) }\end{array}$ & 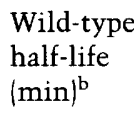 \\
\hline $\begin{array}{l}\text { ompA }+4^{\mathrm{c}} \\
\text { (pseudo-wild-type) }\end{array}$ & & $19 \pm 2^{d}$ & ND \\
\hline $\begin{array}{l}\text { ompAs } 64^{\mathrm{e}} \\
(\Delta \mathrm{hpl})\end{array}$ & & $5.7 \pm 0.7$ & $16 \pm 2$ \\
\hline $\begin{array}{l}\text { ompAs } 104-114^{\mathrm{c}, \mathrm{f}} \\
\left(\Delta 5^{\prime}-\mathrm{ss} 2\right)\end{array}$ & & $9.5 \pm 0.8$ & $18 \pm 1$ \\
\hline $\begin{array}{l}\text { ompA } 474-103^{\mathrm{c}} \\
(\Delta \mathrm{hp} 2)\end{array}$ & \{ & $14 \pm 1$ & $14 \pm 1$ \\
\hline $\begin{array}{l}\text { ompA } A 65-104^{\mathrm{g}} \\
(\Delta \mathrm{ss} 1, \mathrm{hp} 2)\end{array}$ & \} & $17 \pm 1$ & $19 \pm 1$ \\
\hline $\begin{array}{l}\text { ompAD104, }{ }^{\mathrm{d}, \mathrm{e}} \\
(\Delta \mathrm{hp1}, \mathrm{ss} 1, \mathrm{hp} 2)\end{array}$ & - & $4.4 \pm 0.2$ & $17 \pm 3$ \\
\hline $\begin{array}{l}\operatorname{omp} A \Delta 115^{\mathrm{e}, \mathrm{f}} \\
\left(\Delta \mathrm{hpl}, \mathrm{ss} 1, \mathrm{hp} 2,5^{\prime}-\mathrm{ss} 2\right)\end{array}$ & & $3.6 \pm 0.6^{\mathrm{d}}$ & $19 \pm 4$ \\
\hline
\end{tabular}

${ }^{a}$ The expected secondary structure of each mutant $5^{\prime}$ UTR is represented diagrammatically (for a detailed secondary structure of the wild-type 5' UTR, see Fig. 1). All were transcribed from the bla promoter, whose transcription initiation site was mapped precisely by primer extension (data not shown). (Solid line) Retained 5' UTR segment; (dotted or absent line) deleted 5' UTR segment; (solid rectangle) Shine-Dalgarno element.

'The half-life of the endogenous wild-type $\operatorname{ompA}$ message was measured simultaneously in the same strain as each mutant transcript. (ND) Not determined.

'The ompA+4, ompAD74-103, and ompAD104-114 5' UTRs differ at the $5^{\prime}$ end from that of wild-type ompA mRNA in that the $5^{\prime}$-terminal $\mathrm{G}$ has been replaced by the sequence GAUCA. The last 3 nucleotides of this substituted pentanucleotide (UCA) are expected to augment hpl by 2 bp by pairing with the last nucleotide of $\mathrm{hpl}(\mathrm{U})$ and the first 2 nucleotides of ss $\mathrm{l}$ (GA) (see Table 2).

${ }^{\mathrm{d}}$ Emory and Belasco (1990).

'In addition to deletion of the number of 5'-terminal nucleotides indicated by the ompA allele name, 4 nucleotides (GAUC) have been added at the $5^{\prime}$ end of ompAD64 mRNA, and 6 nucleotides (GAUCAG) have been added at the $5^{\prime}$ end of ompAD104 and ompAD115 mRNA.

fSegment 5'-ss 2 comprises ompA nucleotides 104-114.

II ompA 65 -104 mRNA, the G-U pair normally at the bottom of hpl has been changed to an A-U pair, and hpl has been augmented at its base by 4 additional nucleotide pairs (GAUChp1-GAUC). Furthermore, the deleted RNA segment (ss1-hp2) has been replaced by 2 nucleotides (AG).

Owing to the presence of the wild-type ompA transcript in strain C600S, it was unclear initially whether the rapid disappearance of the extended ompA messages represented mRNA degradation or mere removal of the single-stranded portion of the $5^{\prime}$ extension to generate a stable processing product resembling wild-type ompA

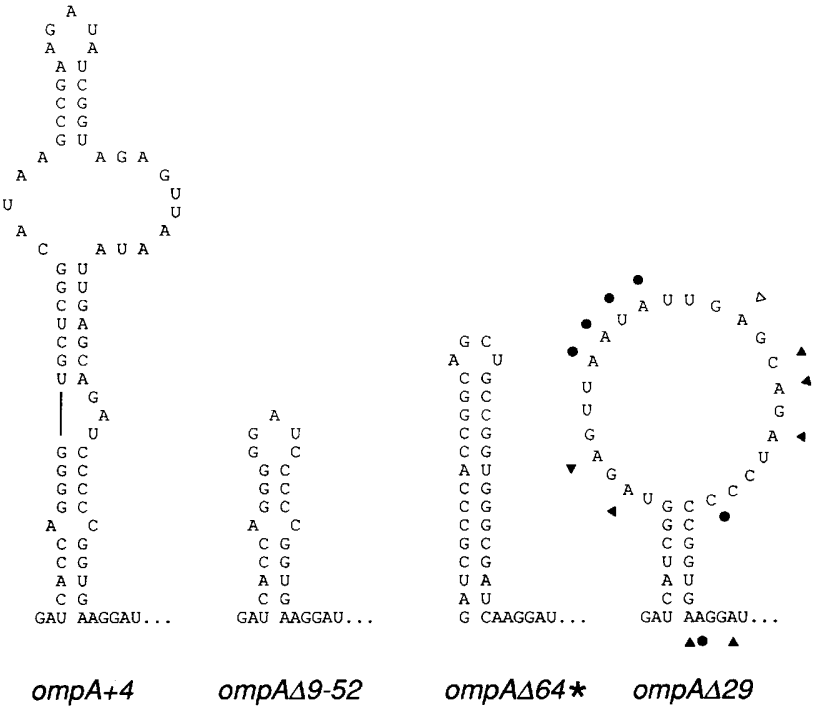

Figure 3. Variant $5^{\prime}$ stem-loop structures. For each ompA message with an altered $5^{\prime}$ hairpin, the sequence and expected secondary structure of a $5^{\prime}$-terminal RNA segment that extends into ssl are shown. In every case, the remainder of the mRNA sequence is identical to that of the wild-type ompA transcript. Adenosine, cytosine, and uridine residues susceptible to significant methylation by DMS in $E$. coli are indicated for the $5^{\prime}$ terminal segment of $\operatorname{omp} A \Delta 29$ mRNA. (O) Heavy methylation; $(\Delta)$ moderate methylation; $(\triangle)$ weak methylation.

mRNA. If stable, such a processing product would be expected to accumulate in the cell to a steady-state concentration higher than that of its more labile precursors, the full-length ompA transcripts with $5^{\prime}$ extensions. To distinguish these possibilities, RNA was isolated from an isogenic host strain (SE600) that bore a chromosomal deletion of the ompA gene and carried plasmid pOMPA + 16a or pOMPA + 16b. S1 and primer-extension analysis of these steady-state RNA samples showed little or no detectable omp $A+16 a$ or omp $A+16 b$ mRNA processing product that was similar in length to the wildtype ompA message (Fig. 5, control lanes; Fig. 6). Therefore, addition of a short, single-stranded RNA segment to

Table 2. Half-lives of mutant ompA transcripts with variant 5 ' hairpins

\begin{tabular}{lcc}
\hline & \multicolumn{2}{c}{ Half-life (min) } \\
\cline { 2 - 3 } omp $A$ allele & $\begin{array}{l}\text { mutant } \\
\text { message }\end{array}$ & $\begin{array}{l}\text { wild-type } \\
\text { message }^{\mathrm{a}}\end{array}$ \\
\hline omp $A+4$ & $19 \pm 2^{\mathrm{b}}$ & $\mathrm{ND}$ \\
omp $A \Delta 9-52$ & $13 \pm 1$ & $18 \pm 2$ \\
omp $A \Delta 64 *$ & $12 \pm 1$ & $18 \pm 3$ \\
omp $A \Delta 29$ & $15 \pm 2$ & $17 \pm 2$ \\
\hline
\end{tabular}

${ }^{\mathrm{a}}$ The half-life of the endogenous wild-type ompA message in each strain was measured simultaneously. (ND) Not determined.

${ }^{b}$ Emory and Belasco (1990). 
Table 3. Mutant ompA transcripts with or without destabilizing 5' extensions

\begin{tabular}{|c|c|c|c|}
\hline omp $A$ allele & $\begin{array}{l}\text { 5' UTR } \\
\text { structure }^{\text {a }}\end{array}$ & $\begin{array}{l}\text { Mutant } \\
\text { half-life } \\
\text { (min) }\end{array}$ & $\begin{array}{l}\text { Wild-type } \\
\text { half-life } \\
(\min )^{\mathrm{b}}\end{array}$ \\
\hline $\begin{array}{l}\text { ompA } \\
\text { ompA }+4\end{array}$ & & $19 \pm 2^{c}$ & $\begin{array}{c}17 \pm 2 \\
\mathrm{ND}\end{array}$ \\
\hline $\begin{array}{l}o m p A+12 a \\
o m p A+16 a \\
o m p A+16 b\end{array}$ & & $\begin{array}{l}3.2 \pm 1.1 \\
5.8 \pm 0.3 \\
6.2 \pm 0.8\end{array}$ & $\begin{array}{l}15 \pm 3 \\
16 \pm 2 \\
12 \pm 1\end{array}$ \\
\hline $\begin{array}{l}o m p A+12 a^{*} \\
\text { ompA } A+16 b^{*}\end{array}$ & & $\begin{array}{l}13 \pm 1 \\
13 \pm 1\end{array}$ & $\begin{array}{l}17 \pm 1 \\
15 \pm 1\end{array}$ \\
\hline omp $A \Delta 73 a$ & & $6.0 \pm 0.3$ & $14 \pm 1$ \\
\hline omp $A \Delta 73 b$ & ? & $13 \pm 1$ & $15 \pm 1$ \\
\hline ompAD104* & - & $24 \pm 3$ & $19 \pm 3$ \\
\hline
\end{tabular}

${ }^{a}$ The secondary structure of each mutant 5' UTR is represented diagrammatically. Only 5 '-terminal single-stranded extensions $>2$ nucleotides in length are shown. (Solid rectangle) ShineDalgarno element; (1) ompA hp1; (2) ompA hp2; (*) synthetic hp*.

${ }^{\mathrm{b}}$ The half-life of the endogenous wild-type ompA message in each strain was measured simultaneously. (ND) Not determined. 'Emory and Belasco (1990).

the 5' end of ompA mRNA destabilizes the entire transcript.

Five unpaired nucleotides at the $5^{\prime}$ end can destabilize ompA mRNA

An ompA deletion mutant (ompA $\Delta 73 a$ ) lacking hpl and ss 1 and beginning instead with hp2-ss 2 preceded by just 5 nucleotides (GAUCA) decays with a short half-life $(6.0 \pm 0.3 \mathrm{~min})$ compared with wild-type ompA mRNA (14 $\pm 1 \mathrm{~min}$ ) (Table 3 ; Fig. 7). As a $5^{\prime}$ hairpin of any kind and ss 2 appear to be the only features of the $\operatorname{ompA} 5^{\prime}$ UTR that are necessary for mRNA longevity, the short lifetime of ompA $\Delta 73 a$ mRNA suggests that a $5^{\prime}$-terminal single-stranded segment only 5 nucleotides in length may be enough to accelerate ompA mRNA degradation. This hypothesis was confirmed by measuring the decay rate of a message $(o m p A \Delta 73 b)$ that is identical to ompA $\Delta 73 a$ except that it has only 1 nucleotide (A) upstream of hp2-ss2 (Table 3). As expected, the half-life of omp $A \Delta 73 b \mathrm{mRNA}(13 \pm 1 \mathrm{~min})$ proved to be about as long as that of the wild-type ompA transcript (15 \pm 1 min) (Fig. 7). These findings indicate that as few as 5 unpaired bases at the $5^{\prime}$ end are sufficient to target ompA mRNA for rapid degradation in E. coli.
Addition of a 5'-terminal stem-loop can prolong the lifetime of a normally short-lived mRNA

As a final demonstration that a $5^{\prime}$ stem-loop and the single-stranded RNA segment encompassing the ompA ribosome-binding site are sufficient for the full efficacy of the ompA mRNA stabilizer, a minimal 5' UTR comprising only a synthetic terminal hairpin (hp*) and the ompA ss 2 segment was evaluated. As shown in Figure 7, an ompA transcript bearing this minimal $5^{\prime}$ UTR (ompAD104*; Table 3 ) is as stable as the wild-type message. It is also five times more stable than a similar mes-
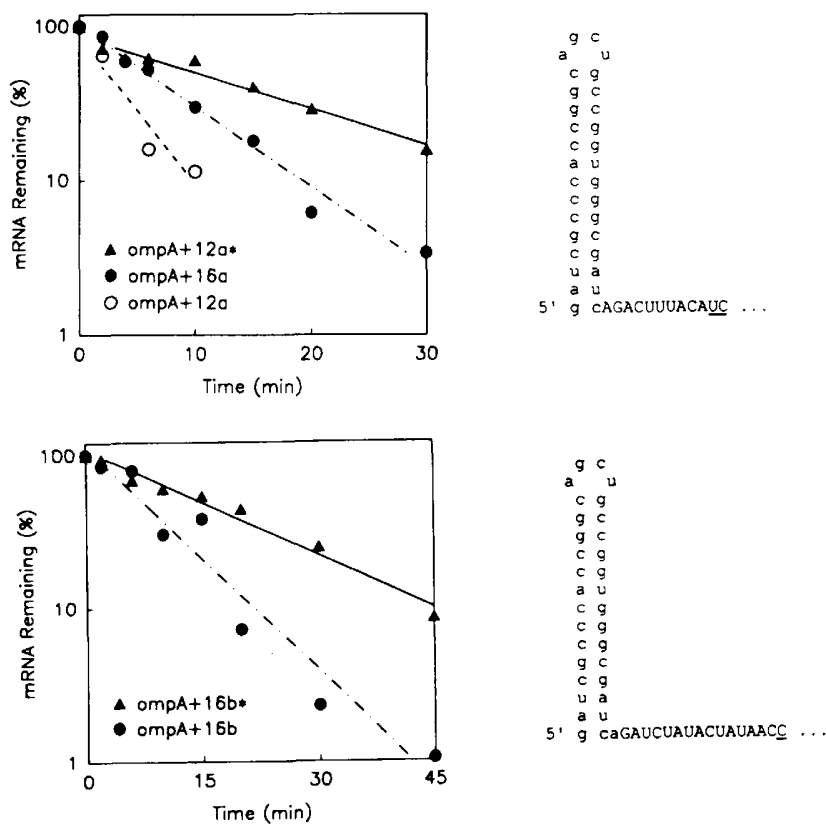

Figure 4. Decay of mutant $\operatorname{omp} A$ transcripts with $5^{\prime}$ extensions. After transcription inhibition, total cellular RNA was isolated periodically from $E$. coli strain C600S containing pOMPA $+12 a$, pOMPA $+16 a$, or pOMPA $+12 a *$ (top) or containing pOMPA $+16 \mathrm{~b}$ or pOMPA $+16 \mathrm{~b} *$ (bottom). The mutant transcripts and the endogenous wild-type ompA message were detected by $\mathrm{S} 1$ analysis, and mRNA concentration was plotted semilogarithmically as a function of time. Beside the graphs are drawn the $5^{\prime}$ extensions of ompA+12a* (top) and ompA+16b* (bottom) mRNA. The $5^{\prime}$ extensions of ompA+12a and omp $A+16 b$ mRNA are related to those of ompA+12a* and omp $A+16 b^{*}$ mRNA, respectively, but include only those nucleotides shown in uppercase letters. The $5^{\prime}$ extension of ompA + 16a mRNA is identical to that of ompA $+12 a$ except for 4 additional nucleotides (GAUC) at the $5^{\prime}$ end. Underlined nucleotides at the $3^{\prime}$ end of each extension are expected to basepair with the first $1-2$ nucleotides of $5^{\prime}$ UTR segment ss 1 . Transcription initiation sites for these messages were mapped precisely by primer extension (data not shown). The measured halflives were $3.2 \pm 1.1 \mathrm{~min}$ for ompA $+12 a \mathrm{mRNA}(O)$ and $15 \pm 3$ min for wild-type ompA mRNA (top), $5.8 \pm 0.3 \mathrm{~min}$ for ompA + 16a mRNA (1) and $16 \pm 2$ min for wild-type ompA mRNA (top), $13 \pm 1 \mathrm{~min}$ for ompA+12a* mRNA (A) and $17 \pm 1 \mathrm{~min}$ for wild-type ompA mRNA $\mid$ top $\mid, 6.2 \pm 0.8 \mathrm{~min}$ for $o m p A+16 b$ mRNA $(O)$ and $12 \pm 1 \mathrm{~min}$ for wild-type ompA mRNA (bottom), and $13 \pm 1 \mathrm{~min}$ for ompA $+16 b *$ mRNA ( $\Delta$ ) and $15 \pm 1 \mathrm{~min}$ for wild-type ompA mRNA (bottom). 
sage (ompA $\Delta 104$ ) with a 5' UTR consisting only of the ss2 segment (Table 1; Fig. 7). This finding confirms that a simple 5 '-terminal hairpin and the ompA ss 2 segment together are as effective as the complete $0 m p A 5^{\prime}$ UTR at stabilizing mRNA. Moreover, when the same synthetic stem-loop (hp*) was introduced at the $5^{\prime}$ terminus of bla mRNA, which encodes $\beta$-lactamase, the resulting bla202 messages were found to decay with a half-life of $6.8 \pm 0.4 \mathrm{~min}$ (Fig. 7), about twice the lifetime of wildtype bla mRNA (3.7 $\pm 0.3 \mathrm{~min}$ ) (Fig. 7; von Gabain et al. 1983). Thus, the ability of bla mRNA to resist degradation in $E$. coli can be enhanced simply by adding a stemloop at its $5^{\prime}$ end.

Degradation in the absence of a $5^{\prime}$-terminal stem-loop appears to begin downstream of the ompA $5^{\prime}$ end

In principle, accelerated degradation of ompA mRNA lacking a 5 '-terminal hairpin might be initiated either by a $5^{\prime}$ exonuclease /defined here as a ribonuclease that removes single nucleotides sequentially from the RNA 5' terminus) or by a $5^{\prime}$-end-dependent endonuclease that cuts internally but is sensitive to the presence or absence of secondary structure at the $5^{\prime}$ terminus of mRNA. Of these two possibilities, degradation by a single-strandspecific $5^{\prime}$ exonuclease seems less likely because no $5^{\prime}$ exoribonuclease has ever been detected in $E$. coli and because destabilizing single-stranded extensions added upstream of ompA hpl are not preferentially removed from the $5^{\prime}$ end of ompA+16a and ompA+16b mRNA to generate wild-type-like omp $A$ mRNA as a readily detectable processing product. As $5^{\prime}$ exoribonucleases, by definition, digest RNA from the $5^{\prime}$ end, the plausibility of $5^{\prime}$-exonucleolytic initiation of mRNA decay can be tested further by determining whether degradation of the $5^{\prime}$ mRNA segment is faster or slower than decay of the rest of the message.

Degradation of three different ompA messages without a 5 '-terminal stem-loop (ompA $\Delta 64$, ompA+16a, and $o m p A+16 b$ mRNA) was monitored by S1 analysis with a mixture of two DNA probes, one complementary to the $5^{\prime}$-terminal segment of these transcripts (the 5' UTR and codons 1-37) and the other complementary to an internal ompA segment spanning codons 67-295. By combining these two probes in each $\mathrm{S} 1$ protection assay, differences in the relative decay rates of the two RNA segments could be measured with considerable accuracy. As observed previously for wild-type ompA mRNA /von Gabain et al. 1983), the internal segment of all three of these mutant messages was found to decay more rapidly than the corresponding 5 '-terminal segment (Fig. 8). To demonstrate that the differential lifetimes measured for the 5 '-terminal and internal ompA mRNA segments are independent of the relative lengths of the two DNA probes used simultaneously for $\mathrm{S} 1$ protection, the measurements were repeated with the same 5'-terminal probe and a much shorter internal probe complementary to ompA codons 249-295. Regardless of the length of either the internal probe or the RNA segment with which it hybridized, the same segmental difference in stability was observed for each of the three mutant ompA messages (Fig. 8). In every one of these six independent experiments, the relative concentration of the internal mRNA segment declined steadily to a level between one-third and one-half that of the $5^{\prime}$-terminal segment within $30 \mathrm{~min}$ after transcription inhibition.

Thus, it appears for three different labile ompA transcripts lacking a 5 '-terminal stem-loop that degradation of an internal RNA segment precedes decay of the $5^{\prime}$ UTR. This conclusion is consistent with our finding, for a number of mutant $\operatorname{omp} A$ messages, that there is no correlation in rapidly growing cells between mRNA halflife and the relative steady-state concentration of the major products of endonucleolytic cleavage within the $5^{\prime}$ UTR (data not shown; Lundberg et al. 1990); only when ompA mRNA decay accelerates in slowly growing cells does its rate appear to be controlled by $5^{\prime}$ UTR cleavage (Melefors and von Gabain 1988). Together, our data suggest that under conditions of rapid bacterial growth, the function of the $5^{\prime}$-terminal $\operatorname{omp} A$ hairpin is to protect the message from degradation by a ribonuclease that initiates decay downstream of the $5^{\prime}$ end.

\section{Discussion}

A key to understanding the molecular basis for differential mRNA stability in bacteria is to identify the structural features of stable messages that are responsible for their unusual longevity in vivo. The studies reported here show that a $5^{\prime}$-terminal stem-loop is both crucial to the function of the ompA $5^{\prime}$ UTR as a potent mRNA stabilizer and sufficient to prolong the lifetime of a normally labile E. coli message. Remarkably, the 5'-terminal stem-loop shields ompA mRNA from attack by a cellular ribonuclease that appears to initiate degradation far from the $5^{\prime}$ end.

Our data also indicate that the ompA mRNA stabilizer is bipartite, with a second, distinct domain of functional importance. Both the 5' stem-loop and a single-stranded RNA segment in the vicinity of the ompA ribosomebinding site and its flanking sequences contribute to the remarkable longevity of the $\operatorname{omp} A$ transcript, and together they are sufficient for full activity of the ompA mRNA stabilizer. Alone, each of these elements can stabilize mRNA to a lesser extent. Thus, ompA transcripts that have both stabilizing elements (wild-type, ompA $\Delta 65-104)$ are more stable than ompA messages lacking either the $5^{\prime}$ hairpin or $5^{\prime}$-ss 2 lompA 464 , ompA $\Delta 104$, ompA $\Delta 104-114$ ) which, in turn, are more stable than a message that lacks both of these RNA segments (ompAD115). Similarly, the half-life of bla mRNA, which is increased twofold simply by adding a $5^{\prime}$ stem-loop (bla202), increases about fivefold when its $5^{\prime}$ UTR is replaced with the entire ompA 5' UTR (Belasco et al. 1986; Emory and Belasco 1990).

The longevity of ompAD104* mRNA, in which hpl, ss 1 , and hp2 are replaced by a synthetic stem-loop, rules out any contribution to ompA mRNA stability from pos- 

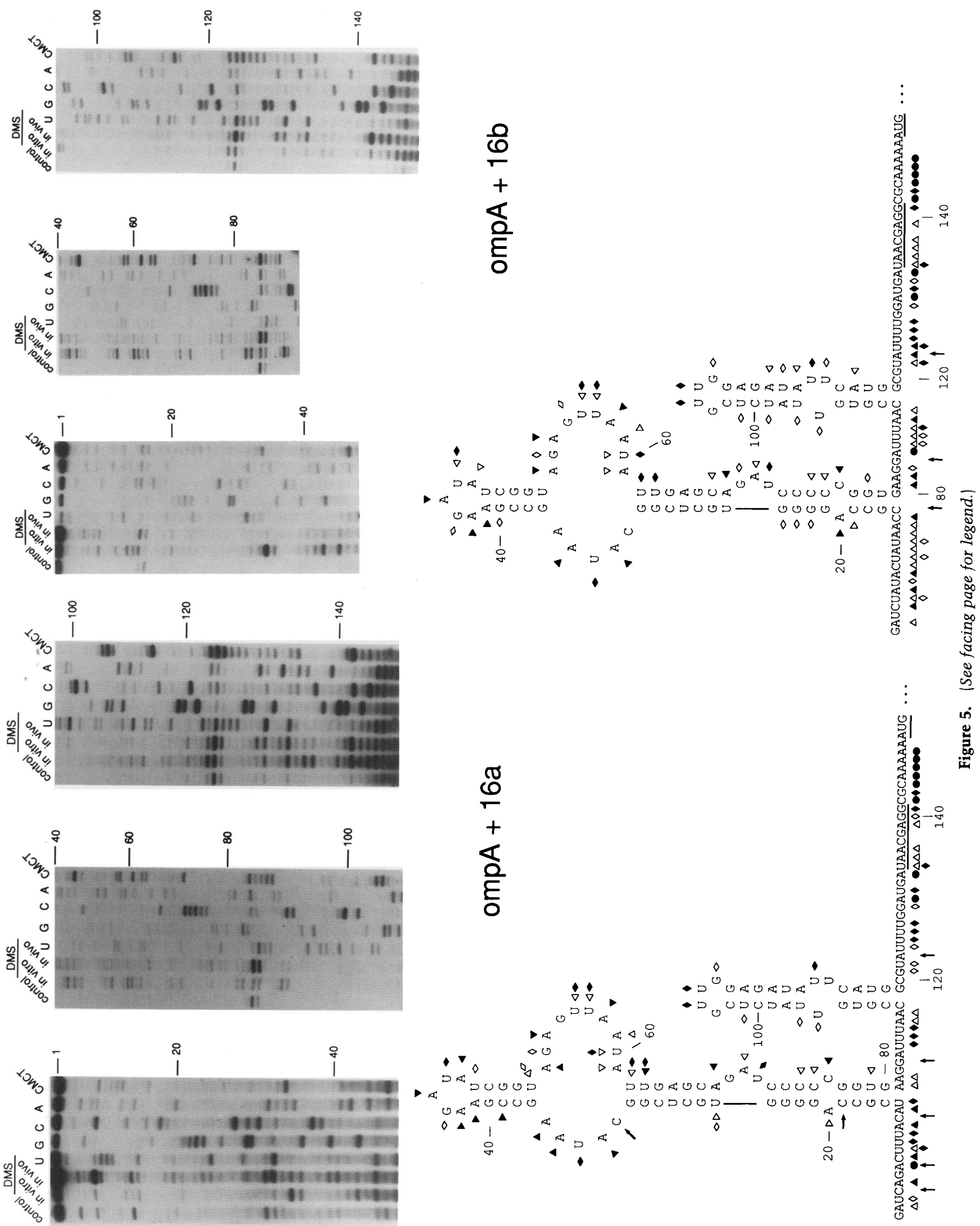
sible sites of translation initiation upstream of ss2. These sites, which were identified on the basis of sequence analysis (Movva et al. 1980), probably are inaccessible to ribosomes due to occlusion by intramolecular base-pairing (Chen et al. 1991).

\section{Stabilization of mRNA by a $5^{\prime}$ stem-loop}

The presence of a $5^{\prime}$-terminal stem-loop can prolong the lifetime of ompA mRNA by as much as a factor of 5 . The location of this stem-loop at or very near the $5^{\prime}$ terminus is crucial to its stabilizing effect, whereas the sequence of this hairpin and its position relative to the ribosomebinding site appear to be of little consequence to message stability. Up to two unpaired nucleotides upstream of the $5^{\prime}$ hairpin (e.g., ompA +4 , ompA $\Delta 29$ ) are tolerated without any reduction in mRNA stability, but the addition of 10-15 unpaired nucleotides of random sequence to the ompA $5^{\prime}$ end lompA+12a, ompA+16a, $o m p A+16 b \mid$ is as destabilizing as deletion of the $5^{\prime}$ hairpin. Moreover, the short lifetime of ompA $\Delta 73 a$ mRNA versus omp $A \Delta 73 b$ mRNA indicates that 5 unpaired bases at the $5^{\prime}$ end are sufficient to accelerate degradation of ompA mRNA, as these two messages are identi$\mathrm{cal}$ in sequence except for the number of nucleotides that precede hp2-ss2. Therefore, the minimum number of $5^{\prime}$ terminal unpaired nucleotides that can destabilize omp $A$ mRNA in E. coli is no more than five and may be as few as three. The destabilizing effect of unpaired bases at the ompA 5' terminus does not appear to be sequence specific.

These findings explain our previous observation that the 5' UTRs of the $S$. marcescens and E. aerogenes ompA transcripts function as very effective mRNA stabilizers in E. coli (Chen et al. 1991). Although these ompA 5' UTRs are quite similar in secondary structure to that of E. coli and the sequence of ss1 and ss 2 is highly conserved $(80 \%)$, there is extensive sequence divergence in hpl and hp2 (Chen et al. 1991). The efficacy of the Ser-

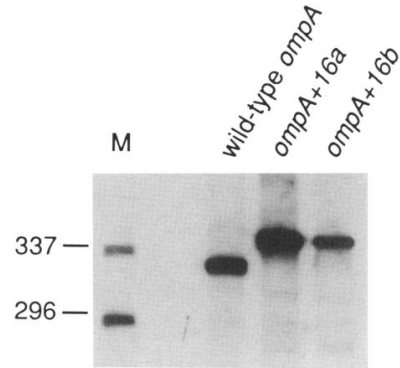

Figure 6. 5 '-End mapping of ompA+16a and ompA+16b mRNA at steady state. Total cellular RNA was isolated from $E$. coli strain C600S or from strain SE600 containing either pOMPA $+16 \mathrm{a}$ or pOMPA $+16 \mathrm{~b}$. The wild-type and mutant ompA transcripts were detected by $\mathrm{S} 1$ analysis with $5^{\prime}$-end-labeled DNA probes complementary to the first $0.32-0.34 \mathrm{~kb}$ of each message. Calibration is in nucleotides. A set of molecular size standards (lane $M$ ) was generated as in Fig. 2.

ratia and Enterobacter ompA 5' UTRs in E. coli, despite numerous hpl and hp2 sequence differences, is now understandable in light of our present finding that virtually any $5^{\prime}$-terminal hairpin followed by ss 2 is sufficient to protect ompA mRNA from rapid degradation.

As the sequence of the $5^{\prime}$ stem-loop is relatively unimportant to message stability and its stabilizing influence is negated by the presence upstream of several unpaired nucleotides, it evidently is the absence of a significant single-stranded RNA segment at the $5^{\prime}$ terminus rather than the presence of ompA hpl that makes messages bearing the ompA 5' UTR resistant to degradation. We note that several other long-lived prokaryotic messages in their mature form (e.g., E. coli papA mRNA, T4 gene 32 mRNA, and Rhodobacter capsulatus pufBA mRNA) have the potential to form a hairpin structure within 1-4 nucleotides of the $5^{\prime}$ end (Fig. 9), (Youvan et al. 1984; Belasco et al. 1985; Gorski et al. 1985; Baga et al. 1988; McPheeters et al. 1988). Together with our present findings, this observation suggests that a $5^{\prime}$

Figure 5. Methylation of $o m p A$ transcripts bearing 5' extensions. (Top) Total cellular RNA was isolated from E. coli strain SE600 containing pOMPA + 16a (left) or pOMPA + 16b (right) after treating each culture with DMS (DMS/in vivo). Alternatively, total cellular RNA was purified from the same cultures without prior DMS treatment and then alkylated in vitro with either DMS (DMS/in vitro) or CMCT. Sites of alkylation within the 5' UTR of ompA+16a and ompA+16b mRNA were mapped by primer extension with AMV reverse transcriptase, using complementary oligodeoxynucleotides (AGCGAAACCAGCCAGTGCCACTGC or GATAACACGGTTAAATCCTTCAC) that annealed to mRNA sequences either 22-45 nucleotides downstream or 50-72 nucleotides upstream of the translation initiation codon of $\mathrm{ompA}+16 a$ and $\mathrm{ompA}+16 \mathrm{~b}$. Gel electrophoresis was performed in parallel with the products of primer extension on unmethylated RNA templates in the presence (lanes $U, G, C, A$ ) or absence (control lane) of dideoxynucleoside triphosphates. The sequencing lanes are labeled to indicate the sequence of the RNA, not the complementary DNA. Blockage of primer extension by an alkylated RNA base results in a complementary DNA fragment that is 1 nucleotide shorter than that arising from incorporation of a dideoxynucleotide opposite the same RNA base. Calibration is in nucleotides from the mRNA $5^{\prime}$ end. (Bottom) Summary of alkylation data for the 5' UTRs of ompA +16a (left) and ompA +16b (right) mRNA. Adenosine, cytosine, and uridine residues susceptible to significant methylation by DMS in $E$. coli are indicated. $(\boldsymbol{O})$ Heavy methylation; $(\mathbf{\Delta})$ moderate methylation; $(\triangle)$ weak methylation. Also labeled are uridine and guanosine residues that are significantly alkylated by CMCT in vitro. $|\downarrow|$ Heavy-tomoderate alkylation; $(\diamond)$ weak alkylation. Comparisons of susceptibility to alkylation are meaningful only among nucleotides within the same message and at a similar distance from the annealed primer. Arrows identify the principal sites of termination by reverse transcriptase on an unalkylated template; the structural significance of primer extension products ending at these sites on alkylated RNA is often difficult to assess. Two of these termination sites on unalkylated RNA (at nucleotides 84 and 123) correspond to known RNase K cleavage sites within the ompA 5' UTR (Lundberg et al. 1990); whether or not the others also correspond to RNA 5' ends is uncertain. No differences were observed between the alkylation patterns of the ompA+12a (data not shown) and ompA+16a $5^{\prime} \mathrm{UTR}$. 
Figure 7. Degradation of a variant $o m p A$ transcript bearing a minimal 5' stabilizer preceded by 0,1 , or 5 nucleotides and of bla mRNA with an added 5'-terminal stem-loop. After transcription inhibition, total cellular RNA was isolated periodically from $E$. coli strain C600S containing pOMPA $\triangle 73 a$ (top left), pOMPA $\triangle 73 b$ (bottom left), pOMPA $104 *$ (top right), pBLA200 (bottom right), or pBLA202 (bottom right). Transcripts of the ompA,

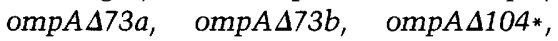
bla200, and bla202 genes were detected by $\mathrm{Sl}$ analysis, and mRNA concentration was plotted semilogarithmically as a function of time. The measured half-lives were $6.0 \pm 0.3 \mathrm{~min}$ for omp $A \Delta 73 a$ mRNA $(\Delta)$ and $14 \pm 1 \mathrm{~min}$ for wild-type ompA mRNA (O) (top left), $13 \pm 1 \mathrm{~min}$ for ompA $\Delta 73 b$ mRNA (A) and $15 \pm 1 \mathrm{~min}$ for wild-type ompA mRNA (O) (bottom left), $24 \pm 3$ min for ompA $\Delta 104 *$ mRNA $(\mathbf{\Delta})$ and $19 \pm 3 \mathrm{~min}$ for wild-type ompA mRNA (O) (top right), $3.7 \pm 0.3 \mathrm{~min}$ for bla200 mRNA (wild-type) (O) and $18 \pm 2$ min for wild-type ompA mRNA (bottom right), and $6.8 \pm 0.4 \mathrm{~min}$ for bla202 mRNA (A) and $17 \pm 2 \mathrm{~min}$ for wild-type ompA mRNA (bottom right). For comparison, decay data for ompAD104 mRNA (口) are also shown (top right; Table 1).
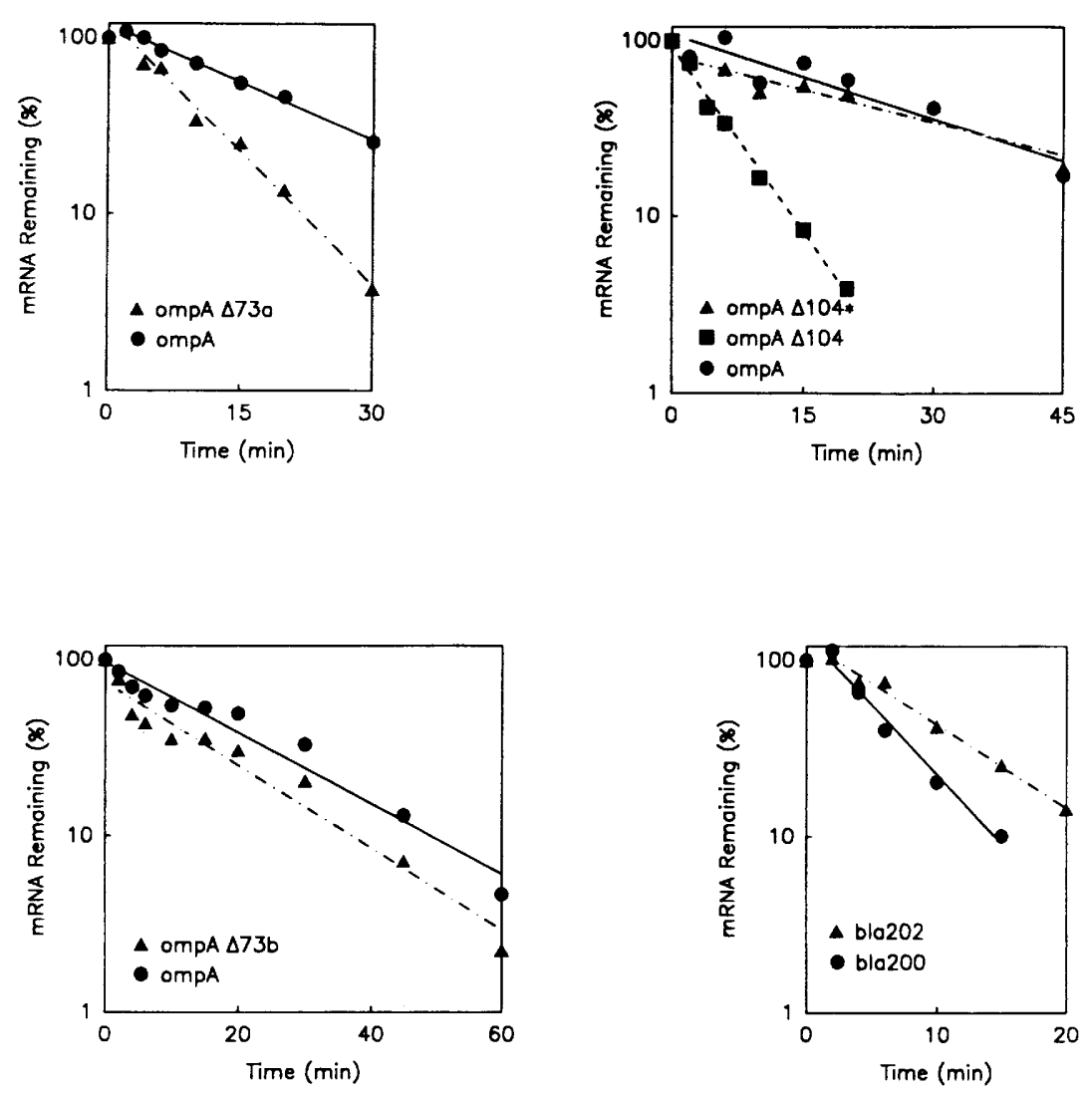

stem-loop may be of general importance as a means by which prokaryotic organisms can selectively enhance the stability of mRNA.

\section{Mechanism of mRNA degradation in $\mathrm{E}$. coli}

The roughly additive contributions to mRNA stability of two distinct structural domains of the ompA $5^{\prime}$ UTR suggest that the degradation of messages that can be stabilized by fusion to this 5' UTR is initiated either by a single ribonuclease whose rate of attack is determined by a combination of $5^{\prime}$ UTR structural features or by a pair of ribonucleases with differing specificities, both of which must be blocked to achieve pronounced mRNA longevity. Undoubtedly there are unstable transcripts whose lability results from attack by a different ribonuclease that is not sensitive to structural features near the mRNA 5 ' end; addition of a 5 '-terminal hairpin or fusion to the entire ompA 5' UTR is not expected to stabilize such messages. Nevertheless, the lifetimes of many short-lived E. coli RNAs (including bla, lacZ, and phoA mRNA) are controlled by the ribonuclease(s) impeded by substituting the ompA $5^{\prime}$ UTR or adding a simple $5^{\prime}$ terminal stem-loop (Belasco et al. 1986; M. Hansen and J. Belasco, unpubl.); and, in principle, all long-lived messages must have structures, sequences, or bound factors that shield them from attack by this enzyme.

Our data therefore suggest that $E$. coli contains a ribonuclease that prefers to attack messages beginning with $>2-4$ unpaired nucleotides. This enzyme is not a $3^{\prime}$ ex- onuclease, as multiple lines of evidence indicate that $b l a$ mRNA degradation, which is slowed by addition of a $5^{\prime}$-terminal hairpin, begins upstream of the $3^{\prime}$ end (von Gabain et al. 1983; Belasco et al. 1986). Instead, the sensitivity of this ribonuclease to base-pairing at the mRNA $5^{\prime}$ terminus indicates that it is either a $5^{\prime}$ exonuclease or a $5^{\prime}$-end-dependent endonuclease that cuts internally but interacts, at least initially, with the $5^{\prime}$ end of mRNA. There are a number of reasons to doubt that the ribonuclease obstructed by the ompA $5^{\prime}$ UTR is a $5^{\prime}$ exonuclease that removes single nucleotides sequentially from the RNA $5^{\prime}$ end. First, as shown previously for the wildtype ompA transcript (von Gabain et al. 1983), rapid degradation of ompA $\Delta 64$, ompA $+16 a$, and omp $A+16 b$ mRNA appears to begin downstream of the $5^{\prime}$ UTR. In addition, degradation of ompA transcripts with either of two single-stranded $5^{\prime}$ extensions does not generate wild-type ompA mRNA as a readily detectable decay intermediate; significant accumulation of such an intermediate might be expected if these messages were degraded by a hypothetical $5^{\prime}$ exonuclease that is impeded when it encounters an RNA stem-loop structure. Third, no $5^{\prime}$ exoribonuclease has ever been detected in E. coli. Finally, inactivation of the ams/rne gene product in $E$. coli stabilizes many RNAs (including ompA mRNA) and inhibits their cleavage in vivo by RNase E or RNase K, two $E$. coli endonucleases that appear to be interrelated and may even be identical (Apirion 1978; Ono and $\mathrm{Ku}-$ wano 1979; Lundberg et al. 1990; Mudd et al. 1990a,b; Babitzke and Kushner 1991; Lin-Chao and Cohen 1991; 

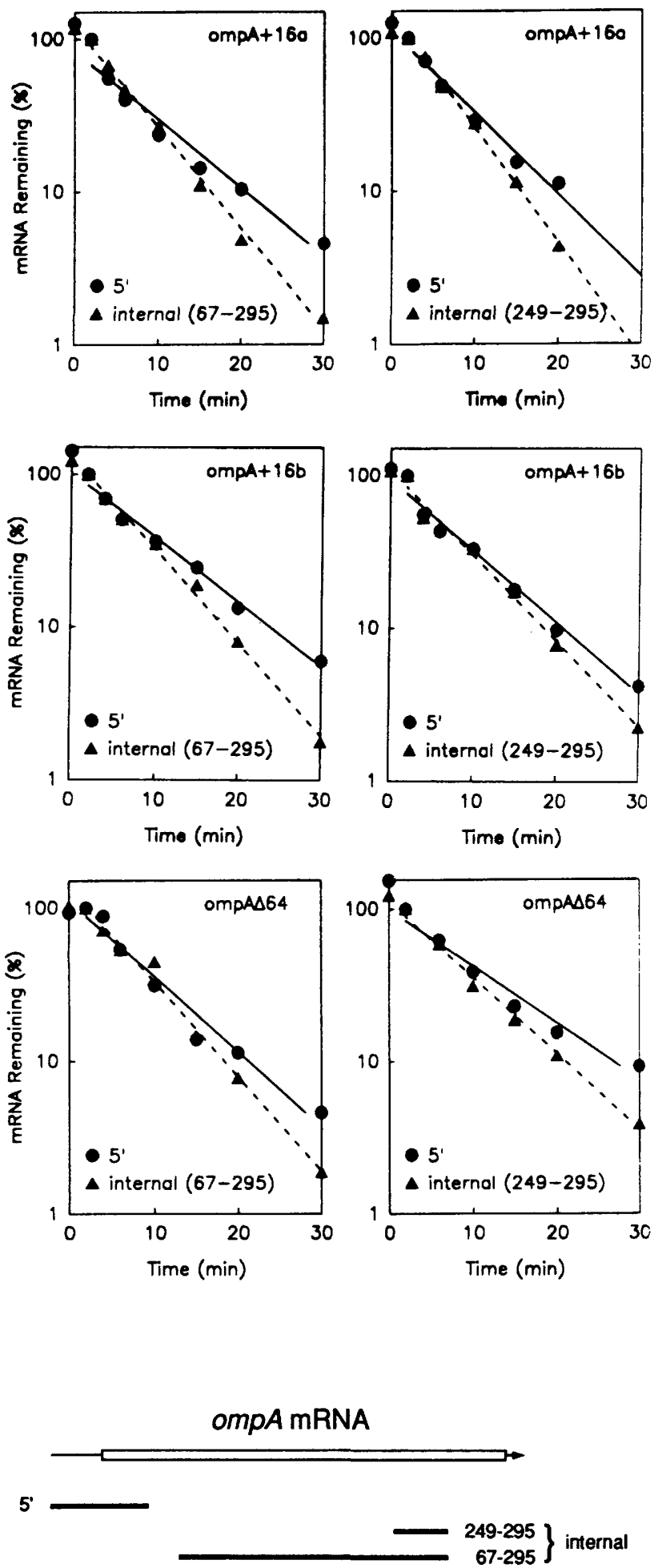

Mackie 1991; Melefors and von Gabain 1991; Nilsson and Uhlin 1991; Taraseviciene et al. 1991); therefore, either or both of these endonucleases are candidates for the key enzyme(s) whose action is impeded by the ompA 5' UTR. It seems likely, therefore, that the ompA 5' UTR protects the ompA message from initial, rate-determin-
Figure 8. Segmental differences in stability within mutant ompA transcripts lacking a 5 '-terminal stem-loop. After transcription inhibition, total cellular RNA was isolated periodically from $E$. coli strain SE600 containing pOMPA $+16 a$, pOMPA $+16 \mathrm{~b}$, or pOMPA $\Delta 64$. The degradation of 5 'terminal and internal segments of each mutant ompA transcript was monitored simultaneously by $\mathrm{S} 1$ analysis with a mixture of two 5 '-end-labeled DNA probes, one complementary to the $5^{\prime}$ UTR plus codons 1-37 and the other complementary either to codons 67-295 or to codons 249-295. (Top) Semilogarithmic plots of the decay of $5^{\prime}$-terminal $(\mathbf{O})$ and internal (A) segments of omp $A+16 a$ (top), omp $A+16 b$ (middle), and ompA $\Delta 64$ (bottom) mRNA, as determined by $\mathrm{S} 1$ analysis with two pairs of segmentspecific probes. In every case, decay of the internal segment is faster than decay of the $5^{\prime}$-terminal segment. (Below) Map of the $5^{\prime}$ and internal ompA mRNA segments detected by $\mathrm{S} 1$ analysis with each probe. (Thin lines) ompA UTRs; (open rectangle) ompA protein-coding region; (arrowhead) ompA 3' end; (thick lines) ompA mRNA segments complementary to each of the three probes.

ing endonucleolytic cleavage at one or more sites downstream of the $5^{\prime}$ end. The precise location of these sites is currently under investigation.

If the enzyme that is impeded by the ompA $5^{\prime}$ UTR is an endonuclease (i.e., a ribonuclease that cuts internally), then the rate of mRNA cleavage by this endonuclease is determined not only by the presence of RNA sequences that can serve as cleavage sites but also by the presence or absence of structures near the mRNA $5^{\prime}$ end that can control access to these sites. Indeed, the ability of a $5^{\prime}$-terminal stem-loop to shield an entire transcript from degradation suggests that the primary determinant of mRNA half-life may often be the accessibility of potential cleavage sites rather than their number or their intrinsic susceptibility to cleavage. This protective effect of a 5' stem-loop suggests a degradation mechanism for $E$. coli messages that can be stabilized by fusion to the ompA 5' UTR, whereby a rate-determining, 5'-end-dependent endonuclease first binds in a structure-dependent step to the mRNA $5^{\prime}$ end or to a protein bound there

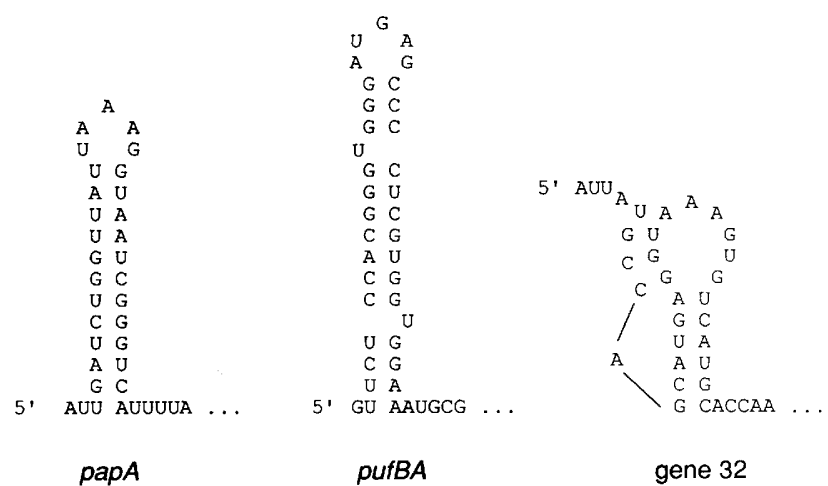

Figure 9. Stem-loop structures near the $5^{\prime}$ end of stable prokaryotic mRNAs. The sequence and likely secondary structure is shown for a $5^{\prime}$-terminal untranslated segment of $E$. coli papA mRNA, $R$. capsulatus pufBA mRNA, and T4 gene 32 mRNA (McPheeters et al. 1988). 
and then seeks out cleavage sites downstream. The RNA fragments thereby generated could be rapidly degraded to mononucleotides by further endonuclease cleavage and exonuclease digestion.

The influence of a $5^{\prime}$-terminal structural element on the stability of mRNA bears a striking resemblance to the selective degradation of proteins on the basis of their amino-terminal amino acid residue (Varshavsky et al. 1988). Moreover, the apparent effect of an upstream structural element on mRNA cleavage at downstream sites is reminiscent of cellular regulatory mechanisms that control transcription and translation rates via sequence elements located upstream of initiation sites for RNA or protein synthesis.

\section{Materials and methods}

Bacterial strains and plasmids

E. coli K-12 strains C600S and SE600 (Nilsson et al. 1987) are streptomycin-resistant, supE44- variants of strain C600. SE600 is identical to C600S except for a deletion of the chromosomal ompA gene (Emory and Belasco 1990).

Plasmid constructions were confirmed by restriction mapping and DNA sequencing. When necessary, protruding DNA ends were made blunt prior to ligation by treatment with T4 DNA polymerase, the Klenow fragment of DNA polymerase I, or mung bean nuclease. Oligonucleotide-directed mutagenesis was performed as described previously (Kunkel 1985; Nakamaye and Eckstein 1986) using purified oligodeoxynucleotides synthesized on an Applied Biosystems $381 \mathrm{~A}$ instrument.

Plasmid pOMPA +4 is a pBR322 derivative that encodes a pseudo-wild-type omp $A$ message transcribed from the bla promoter (Emory and Belasco 1990); this plasmid has a BclI site at the ompA +4 transcription initiation site. Plasmid pOMPA+ $4+3$ was constructed by oligonucleotide-directed insertion of 3 bp (ATC) into pOMPA +4 to create a second Bcll site at the promoter-distal end of the segment encoding hpl (GTGAA $\rightarrow$ GTGATCAA). Deletion of the 0.07-kb Bcll fragment of pOMPA $+4+3$ generated pOMPA $\Delta 64$. Plasmids pOMPA $\Delta 29$ and pOMPA $\triangle 73 \mathrm{a}$ were constructed by deleting from pOMPA $+4 \mathrm{a}$ 0.03-kb Bcll (filled-in)-EcoRV fragment or a 0.08-kb Bcll (filledin)-HphI (T4 DNA polymerase) fragment, respectively, thereby reconstituting the $B c$ II site. Plasmid pOMPA $\Delta 73 \mathrm{~b}$ was constructed by cleaving pOMPA $\Delta 73 \mathrm{a}$ with $B c l \mathrm{I}$, treating the linearized DNA with mung bean nuclease, and religating the resulting blunt ends. The $5^{\prime}$ terminus of ompA $\Delta 73 b$ mRNA mapped to 1 nucleotide upstream of $\mathrm{ompA} \mathrm{hp} 2$, and DNA sequencing of pOMPA $\Delta 73 \mathrm{~b}$ revealed the unexpected loss of one additional base pair upstream of the four that were planned. Plasmid pOMPA $\Delta 74-103$ was constructed by oligonucleotide-directed deletion of a 30-bp pOMPA + 4 fragment that encodes hp 2 and the preceding nucleotide; this mutation created a $S n a \mathrm{BI}$ at the site of deletion. Plasmid pOMPA $\Delta 104$ was created by deleting the $0.08-\mathrm{kb} B c l \mathrm{I}-\mathrm{Sn} a \mathrm{BI}$ fragment of pOMPA $\Delta 74-103$, after first adapting the SnaBI end with a BclI linker (CTGATCAG) and cleaving the linker with $B c l$ I. Insertion of the $0.06-\mathrm{kb} B c l$ fragment of pOMPA $+4+3$ in its natural orientation into the $B c l \mathrm{I}$ site of pOMPA $\triangle 104$ generated pOMPA $\triangle 65-104$. Plasmids pOMPA $\triangle 9-52$ and pOMPA $\Delta 104-114$ were constructed by oligonucleotide-directed deletion from pOMPA +4 of either a 44-bp fragment encoding the top of hp1 or an 11-bp fragment encoding the first 11 nucleotides of ss2, respectively.

Plasmid pOMPA + 16a was created by cloning a $1.28-\mathrm{kb} A c c \mathrm{I}$ (filled-in)-PstI ompA fragment of pTU100 (Bremer et al. 1980) between the BclI (filled-in) and PstI sites of pJB322 (Belasco et al. 1986), thereby reconstituting the BclI site. Plasmid pOMPA $+12 a$ was constructed by cleaving pOMPA + 16a with BclI, removing the protruding ends with mung bean nuclease, and religating the resulting blunt ends. Plasmid pOMPA $+21 \mathrm{~b}$ was constructed by oligonucleotide-directed insertion of $17 \mathrm{bp}$ (GATCTATACTATAACCG) at a site immediately promoter-distal to the $B c$ II recognition sequence of pOMPA +4 , thereby creating a $B g I I I$ site adjacent to the BcII site (TGATCAGATCTATACTATAACCG). Plasmid pOMPA $+16 \mathrm{~b}$ is nearly identical to pOMPA +21 b but lacks the 5-bp BclI-BglII fragment. Insertion of a symmetrical DNA linker (GCCCACCGGCAGCTGCCGGTGGGC) into the BclI site (filled-in) of pOMPA $\triangle 64$, pOMPA + 16a, pOMPA + 2lb, pOMPA $\Delta 104$, and pBLA200 (Emory and Belasco 1990) created pOMPA $\triangle 64 *$, pOMPA + 12a*, pOMPA + 16b*, pOMPA $\triangle 104 *$, and pBLA202, respectively.

Plasmid pOMPA $\triangle 331$ was constructed by deleting a $0.33-\mathrm{kb}$ $B c l l$ (filled in)-HpaI fragment from pOMPA $+16 \mathrm{a}$, thereby reconstituting the BclI site. Plasmid pPB101 was created by inserting a $0.39-\mathrm{kb}$ BamHI-Pst fragment of pOMPA + 16a between the BamHI and PstI sites of pUC19.

\section{Measurement of mRNA lifetimes}

Bacterial culture at $30^{\circ} \mathrm{C}$ in supplemented LB medium, RNA extraction, S1 analysis, and calculation of mRNA half-lives were performed as described previously (Emory and Belasco 1990). All strains grew rapidly under these conditions, with doubling times between 34 and $44 \mathrm{~min}$. Quantitation of S1-protection data was accomplished either by autoradiography and densitometry (Emory and Belasco 1990) or by gel scanning on a Molecular Dynamics model 400 PhosphorImager. Half-lives were calculated by least-squares analysis of semilogarithmic plots of mRNA concentration versus time. Half-life errors were estimated from the standard deviation of the slope of each plot.

Three different $5^{\prime}$-end-labeled DNA fragments of pOMPA + 16a were used as probes to monitor the decay of wild-type ompA mRNA and most variants thereof. $\mathrm{S} 1$ analysis with any of these probes (a 1.2-kb BgIII-EcoRI DNA fragment, a 0.6-kb BstEIIEcoRI fragment, or a 0.6-kb HindIII-EcoRI fragment), which have been described previously (Emory and Belasco 1990), gives the same half-life for the wild-type omp $A$ transcript because all three probes extend beyond the $3^{\prime}$ boundary of the comparatively stable $5^{\prime}$-terminal segment of ompA mRNA. Decay of $o m p A+16 b$ and $o m p A+16 b *$ mRNA was monitored by $\mathrm{S} 1$ analysis with a $0.6-\mathrm{kb}$ HindIII-EcoRI fragment of a pOMPA $+16 \mathrm{~b} *$ point mutant, which was 5 -labeled at a HindIII site created by oligonucleotide-directed mutagenesis at a site corresponding to ompA codon 94. Differential decay of segments within the ompA $+16 a$, ompA $+16 b$, and ompA $\Delta 64$ messages was monitored by simultaneous $\mathrm{S} 1$ analysis with two segment-specific probes labeled at the $5^{\prime}$ end: a 0.46-kb AvaIIHindIII fragment of pOMPA + 16a complementary to the $5^{\prime}$ UTR plus codons $1-37$, and either a $0.86-\mathrm{kb} B g I I I-E c o R I$ fragment of pOMPA $\Delta 331$ complementary to codons $67-295$ or a 0.16-kb BgIII-EcoRI fragment of pPB101 complementary to codons 249-295. Comparative 5'-end-mapping of ompA, omp $A+16 a$, and omp $A+16 b$ mRNA was performed by $\mathrm{S} 1$ analysis with a $0.5-\mathrm{kb}$ BstEII-EcoRI fragment of either pOMPA + 16a or pOMPA $+16 \mathrm{~b}$. Decay of bla200 and bla202 mRNA was monitored by $\mathrm{S} 1$ analysis with a $5^{\prime}$-labeled $1.03-\mathrm{kb}$ HinfI-HindIII fragment of pBLA200.

\section{Probing of RNA secondary structure with DMS}

Methylation of RNA by DMS in E. coli and in vitro, alkylation of RNA with CMCT in vitro, and mapping of reactive nucle- 
otides were performed as described previously (Moazed et al. 1986; Chen et al. 1991). Bacteria for DMS and CMCT alkylation (SE600/pOMPA + 12a, SE600/pOMPA + 16a, SE600/pOMPA + 16b, or SE600/pOMPA $\triangle 29$ | were grown and harvested under the same conditions as were employed for measurements of mRNA stability. Two 5'-end-labeled DNA oligonucleotides (AGCGAAACCAGCCAGTGCCACTGC or GATAACACGGTTAAATCCTTCAC) were used as primers to map methylation sites within the $5^{\prime}$ UTR of ompA mRNA variants. These primers annealed to mRNA sequences 22-45 nucleotides downstream or 50-72 nucleotides upstream of the ompA translation initiation codon, respectively, and they were extended at $55^{\circ} \mathrm{C}$ with AMV reverse transcriptase (Boehringer).

\section{Acknowledgments}

We thank L.-H. Chen, I. Laird-Offringa, and C. Wellington for their helpful comments and M. Hansen for a plasmid construction. This work was supported by U.S. Public Health Service grant GM35769 to J.G.B. from the National Institutes of Health, a National Science Foundation Graduate Fellowship to S.A.E., and funds from the Association pour la Recherche sur le Cancer to P.B.

The publication costs of this article were defrayed in part by payment of page charges. This article must therefore be hereby marked "advertisement" in accordance with 18 USC section 1734 solely to indicate this fact.

\section{References}

Apirion, D. 1978. Isolation, genetic mapping, and some characterization of a mutation in Escherichia coli that affects the processing of ribonucleic acids. Genetics 90: 659-671.

Babitzke, P. and S.R. Kushner. 1991. The Ams (altered mRNA stability) protein and ribonuclease $\mathrm{E}$ are encoded by the same structural gene of Escherichia coli. Proc. Natl. Acad. Sci. 88: $1-5$.

Baga, M., M. Goransson, S. Normark, and B.E. Uhlin. 1988. Processed mRNA with differential stability in the regulation of E. coli pilin gene expression. Cell 52: 197-206.

Bechhofer, D.H. and D. Dubnau. 1987. Induced mRNA stability in Bacillus subtilis. Proc. Natl. Acad. Sci. 84: 498-502.

Belasco, J.G. and C.F. Higgins. 1988. Mechanisms of mRNA decay in bacteria: A perspective. Gene 72: 15-23.

Belasco, J.G., J.T. Beatty, C.W. Adams, A. von Gabain, and S.N. Cohen. 1985. Differential expression of photosynthesis genes in $R$. capsulata results from segmental differences in stability within the polycistronic $r X c A$ transcript. Cell 40: 171-181.

Belasco, J.G., G. Nilsson, A. von Gabain, and S.N. Cohen. 1986. The stability of $E$. coli gene transcripts is dependent on determinants localized to specific mRNA segments. Cell 46: 245-251.

Bremer, E., E. Beck, I. Hindennach, I. Sonntag, and U. Henning. 1980. Cloned structural gene (ompA) for an integral membrane protein of Escherichia coli K-12. Mol. Gen. Genet. 179: 13-20.

Chen, C.-Y.A. and J.G. Belasco. 1990. Degradation of pufLMX mRNA in Rhodobacter capsulatus is initiated by non-random endonucleolytic cleavage. J. Bacteriol. 172: 4578-4586.

Chen, C.-Y.A., J.T. Beatty, S.N. Cohen, and J.G. Belasco. 1988. An intercistronic stem-loop structure functions as an mRNA decay terminator necessary but insufficient for puf mRNA stability. Cell 52: 609-619.
Chen, L.-H., S.A. Emory, A.L. Bricker, P. Bouvet, and J.G. Belasco. 1991. Structure and function of a bacterial mRNA stabilizer: Analysis of the $5^{\prime}$ untranslated region of ompA mRNA. I. Bacteriol. 173: 4578-4586.

Donovan, W.P. and S.R. Kushner. 1986. Polynucleotide phosphorylase and ribonuclease II are required for cell viability and mRNA turnover in Escherichia coli K-12. Proc. Nat1. Acad. Sci. 83: 120-124.

Emory, S.A. 1991. "Analysis of the Escherichia coli ompA mRNA stabilizer." Ph.D. thesis, Harvard University, Cambridge, Massachusetts.

Emory, S.A. and J.G. Belasco. 1990. The ompA 5' untranslated RNA segment functions in Escherichia coli as a growth-rateregulated mRNA stabilizer whose activity is unrelated to translational efficiency. J. Bacteriol. 172: 4472-4481.

Gorski, K., J.-M. Roch, P. Prentki, and H.M. Krisch. 1985. The stability of the bacteriophage T4 gene 32 mRNA: A 5' leader sequence that can stabilize mRNA transcripts. Cell 43: 461469.

Jaeger, J.A., D.H. Turner, and M. Zuker. 1989. Improved predictions of secondary structures for RNA. Proc. Natl. Acad. Sci. 86: $7706-7710$.

Kennell, D.E. 1986. The instability of messenger RNA in bacteria. In Maximizing gene expression (ed. W.S. Reznikoff and L. Gold), pp. 101-142. Butterworths, Stoneham, Massachusetts.

Kunkel, T.A. 1985. Rapid and efficient site-specific mutagenesis without phenotypic selection. Proc. Natl. Acad. Sci. 82: $488-492$.

Lin-Chao, S. and S.N. Cohen. 1991. The rate of processing and degradation of antisense RNAI regulates the replication of ColE1-type plasmids in vivo. Cell 65: 1233-1242.

Lundberg, U., G. Nilsson, and A. von Gabain. 1988. The differential stability of the Escherichia coli ompA and bla mRNA at various growth rates is not correlated to the efficiency of translation. Gene 72: 141-149.

Lundberg, U., A. von Gabain, and O. Melefors. 1990. Cleavages in the $5^{\prime}$ region of the ompA and bla mRNA control stability: Studies with an $E$. coli mutant altering mRNA stability and a novel endoribonuclease. EMBO J. 9: 2731-2741.

Mackie, G. 1991. Specific endonucleolytic cleavage of the mRNA for ribosomal protein S20 of Escherichia coli requires the product of the ams gene in vivo and in vitro. I. Bacteriol. 173: 2488-2497.

Mayford, M. and B. Weisblum. 1989. Conformational alterations in the ermC transcripts in vivo during induction. $E M B O$ J. 8: 4307-4314.

McPheeters, D.S., G.D. Stormo, and L. Gold. 1988. Autogenous regulatory site on the bacteriophage $\mathrm{T} 4$ gene 32 messenger RNA. J. Mol. Biol. 201: 517-535.

Melefors, O. and A. von Gabain. 1988. Site-specific endonucleolytic cleavages and the regulation of stability of $E$. coli ompA mRNA. Cell 52: 893-901.

1991. Genetic studies of cleavage-initiated mRNA decay and processing of ribosomal 9S RNA show that the Escherichia coli ams and rne loci are the same. Mol. Microbiol. 5: 857-864.

Moazed, D., S. Stern, and H.F. Noller. 1986. Rapid chemical probing of conformation in $16 \mathrm{~S}$ ribosomal RNA and $30 \mathrm{~S}$ ribosomal subunits using primer extension. I. Mol. Biol. 187: 399-416.

Mott, J.E., J.L. Galloway, and T. Platt. 1985. Maturation of Escherichia coli tryptophan operon mRNA: Evidence for 3' exonucleolytic processing after rho-dependent termination. EMBO I. 4: 1887-1891.

Movva, N.R., K. Nakamura, and M. Inouye. 1980. Regulatory 


\section{Emory et al.}

region of the gene for the ompA protein, a major outer membrane protein of Escherichia coli. Proc. Natl. Acad. Sci. 77: 3845-3849.

Mudd, E.A., A.J. Carpousis, and H.M. Krisch. 1990a. Escherichia coli RNase $\mathrm{E}$ has a role in the decay of bacteriophage $\mathrm{T} 4$ mRNA. Genes \& Dev. 4: 873-881.

Mudd, E.A., H.M. Krisch, and C.F. Higgins. 1990b. RNase E, an endoribonuclease, has a general role in the chemical decay of E. coli mRNA: Evidence that rne and ams are the same genetic locus. Mol. Microbiol. 4: 2127-2135.

Nakamaye, K.L. and F. Eckstein. 1986. Inhibition of restriction endonuclease NciI cleavage by phosphorothioate groups and its application to oligonucleotide-directed mutagenesis. $\mathrm{Nu}$ cleic Acids Res. 14: 9679-9697.

Newbury, S.F., N.H. Smith, E.C. Robinson, I.D. Hiles, and C.F. Higgins. 1987. Stabilization of translationally active mRNA by prokaryotic REP sequences. Cell 48: 297-310.

Nilsson, P. and B.E. Uhlin. 1991. Differential decay of a polycistronic Escherichia coli transcript is initiated by RNase E-dependent endonucleolytic processing. Mol. Microbiol. 5: 1791-1799.

Nilsson, G., J.G. Belasco, S.N. Cohen. and A. von Gabain. 1984. Growth-rate dependent regulation of mRNA stability in Escherichia coli. Nature 312: 75-77.

. 1987. Effect of premature termination of translation on mRNA stability depends on the site of ribosome release. Proc. Natl. Acad. Sci. 84: 4890-4894.

Ono, M. and M. Kuwano. 1979. A conditional lethal mutation in an Escherichia coli strain with a longer chemical lifetime of mRNA. I. Mol. Biol. 129: 343-357.

Pedersen, S., S. Reeh, and J.D. Friesen. 1978. Functional mRNA half-lives in E. coli. Mol. Gen. Genet. 166: 329-336.

Sandler, P. and B. Weisblum. 1988. Erythromycin-induced stabilization of ermA messenger RNA in Staphylococcus aureus and Bacillus subtilis. I. Mol. Biol. 203: 905-915.

Taraseviciene, L., A. Miczak, and D. Apirion. 1991. The gene specifying RNase $\mathrm{E}$ ( $r n e)$ and a gene affecting mRNA stability (ams) are the same gene. Mol. Microbiol. 5: 851-855.

Varshavsky, A., A. Bachmair, D. Finley, D. Gonda, and I. Wunning. 1988. The $\mathrm{N}$-end rule of selective protein turnover. In Ubiquitin (ed. M. Rechsteiner), pp. 287-324. Plenum Press, New York.

von Gabain, A., J.G. Belasco, J.L. Schottel, A.C.Y. Chang, and S.N. Cohen. 1983. Decay of mRNA in Escherichia coli: Investigation of the fate of specific segments of transcripts. Proc. Nat1. Acad. Sci. 80: 653-657.

Yamamoto, T. and F. Imamoto. 1975. Differential stability of trp messenger RNA synthesized originating at the trp promoter and $\mathrm{p}_{\mathrm{L}}$ promoter of lambda trp phage. I. Mol. Biol. 92: 289-309.

Youvan, D.C., E.J. Bylina, M. Alberti, H. Begusch, and J.E. Hearst. 1984. Nucleotide and deduced polypeptide sequences of the photosynthetic reaction-center, B870 antenna, and flanking polypeptides from $R$. capsulata. Cell 37: 949-957. 


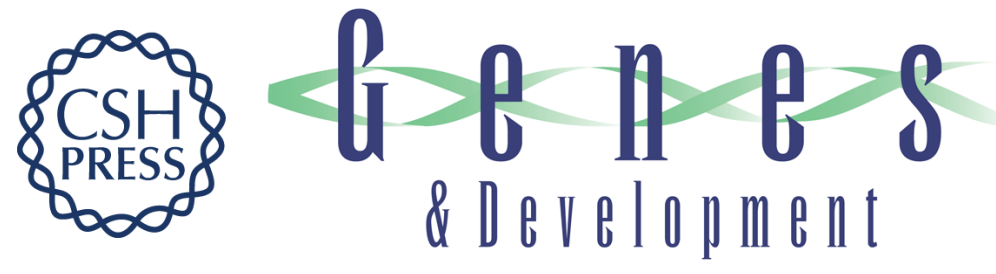

\section{A 5'-terminal stem-loop structure can stabilize mRNA in Escherichia coli.}

S A Emory, P Bouvet and J G Belasco

Genes Dev. 1992, 6:

Access the most recent version at doi:10.1101/gad.6.1.135

References This article cites 41 articles, 14 of which can be accessed free at:

http://genesdev.cshlp.org/content/6/1/135.full.html\#ref-list-1

\section{License}

Email Alerting

Service

Receive free email alerts when new articles cite this article - sign up in the box at the top right corner of the article or click here.

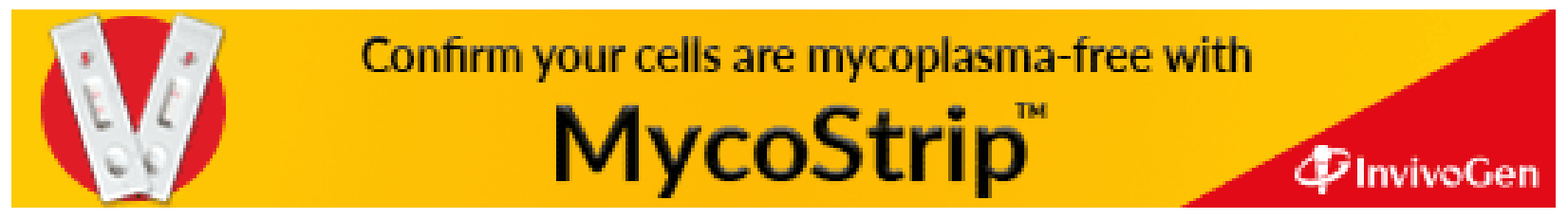

